\title{
Application of Business Niche in Strategic Management: A Study Based on Oriental Idea of Harmony*
}

\author{
Shu Lin \\ School of Business Administration, Jimei University, Xiamen, China \\ Email: shulin@jmu.edu.cn \\ Received 18 January 2015; accepted 4 February 2015; published 10 February 2015 \\ Copyright (C) 2015 by author and Scientific Research Publishing Inc. \\ This work is licensed under the Creative Commons Attribution International License (CC BY). \\ http://creativecommons.org/licenses/by/4.0/ \\ c) (i) Open Access
}

\begin{abstract}
Reviewing the business niche theory, this paper discusses the application in strategic management. Health of a company heavily depends on the harmony of its intra-ecology that has effect on strategy. Also the external surrounding is a significant factor which affects the company's strategic choice. A strategy of dislocation development will reduce direct competition and enhance collaboration. A firm may choose appropriate strategy such as people-oriented policy and performance of corporate social responsibility to maintain the ecological balance of business and enhance its strategic advantage.
\end{abstract}

Keywords

Business Ecology, Oriental Idea, Harmony, Business Niche

\section{Introduction}

As a further development of business strategy and evolution, the theory of business niche explores the source of strategic evolution. It indicates that a business strategy decision, aiming at adapting forwardly, is based on the gap of environments. Companies will extinct in the severe competition without occupying a fit niche. Enterprises build up both competitive and cooperative relationship, which is described as "Harmony" in Chinese, with each other. Yet a unified framework of enterprise has not been created by clearly identified ecological factors. Oriental idea of harmony helps build up a comprehensive framework of internal and external ecology avoiding confusion with business niche, and is useful for applying business niche to strategic management.

\footnotetext{
*The project is supported by the Young Doctor Project of Fujian Province Social Science Program (No. 2014C130) and the Science Founda-
} tion of Jimei University, China (No. Q201207). 


\section{Literature Review}

\subsection{Concept of Business Niche}

Business niche originates in bionomics. The notion of ecological niche, initially raised as a description of the final distribution unit, was named spatial niche [1]. Ecological niche was also defined by functional status [2] or n-dimensional hyper volume [3] in later researches. Next came studies by Odum [4], Colinvaux [5] and Liu et al. [6].

Since 1980s, Chinese scholars have studied on eco-economics theory, which was raised in 1960s by Hesperian and lucubrated in both of macro-perspective and micro-perspective. Eco-economics theory has been applied to enterprise management recent years in China, concentrating on business community and a single company.

Business community niche, namely a macroscopical niche, focuses on how business communities adapt to environment and how environment opts business communities, and analyzes the reason of differentiation of business communities. Individual niche of a company is a microscopical niche researching the relationship between a single company and other companies within a certain business community. Compared with business niche, individual niche of a company does not only combine a single company with a group of relative business but also is applied to make divisions for strategic business [7].

As the n-dimensional hyper volume for description of the resource occupied by enterprises, the niche that is occupied by a whole business community is named by "fundamental niche", moreover the niche that is actually occupied in the fundamental niche by a single enterprise among the community is named "realized niche" [3]. Two views come out based on the aforementioned points: one is niche-width-based view which concentrates on acquisition of larger space for fundamental resource and emphasizes on adjustability to business ecological environment, the other one is resources-division-based view which considers realized niche as a subset of fundamental niche and emphasizes business competitiveness by exploring enterprises development in competitive business environment. Intergrading both of these views, Chinese researchers claim that either a company or an industry occupies a niche in business ecological environment, business niche demonstrates the way a company contends with others. Being dynamic, business niche depends on conscious behaviors [8].

\subsection{Attribute of Business Niche}

In accordance with studies on definitions, business niche is related closely to environmental factors such as location, regulation, technology, customers and so on.

The earliest research declared that technology had significant impact on categories and density of business community [9]. The more enterprises possessing analogous technologies, the greater density of business community is. Subsequently, studies indicate that a strategic group, which is identified by technological factors, comprises of enterprises holding similar innovative ability or occupying homologous niche of technology [10]. A strategic group's activities are subjective to its actual competition position, on which strategic alliance and various investments are based [11] [12].

Trait of system affects business niche. Legality and social esteem of enterprises are constraints to business niche [13]. Also aspects which directly related to resources and production capacity, such as scale, location and price, can largely determine competitive advantage.

Attribute of enterprises and customers and business capacity can be applied to distinguish business niche [14]. Besides some factors like type of geographic distribution, customers and competition of resources supply are approaches to discern business niche [15].

\subsection{Business Niche Applied in Strategic Management}

The application in strategic management concentrates on the nexus for business niche and existence. Beginning with business niche density, the enterprise-to-resource ratio within business community can indicate the relation between enterprises, and be helpful to analyze mortality of enterprises on the niche. If there is competitive relation within a community, the niche density will go in line with the mortality. If the relation is of coexistence, they will run in opposite directions [16] [17].

By scaling the overlap of a single enterprise's business niche, the competitive intensity which enterprises confront may be estimated. Density of the overlap is defined by both period and business niche. Overlap of a single business niche is normally less dense than the one of business community. 
Applied to competitive strategy, the theory of business niche may spawn dislocated business strategy, resources expansion strategy and value chain innovation strategy [18] [19]. Enterprises can also internalize resources by gaining niche, forestalling niche, making an alliance of niche, redistributing resources and learning [20].

\subsection{Reviews on Current Researches}

As an emerging theory, the main problem of business niche theory is the absence of consistent analysis framework. Studies on business niche analysis, consequently, are lack of uniform standard. As a result, interaction among different factors is usually ignored in application of business niche in strategic management.

Additionally, empirical researches in business niche require massive samples and entire past data that is tough to achieve. This situation leads to difficulty of producing conclusion with high universality and reliability.

To sum up, it is imperative that researches on business niche applied in strategic management are based on a new view dominating the attribute of business niche.

\section{The Oriental Idea of Harmony and Business Niche}

Oriental idea of harmony, which is based on traditional culture of China, specializes in human activities throughout the Yellow River Basin, Yangtze River Basin, Indus River Basin, Ganges River Basin, Mesopotamia Basin and Nile River Basin. The essential of oriental thought is harmony, which goes by the name of "He Xie" in Chinese. The oriental idea of harmony embodies the dynamic and balanced relationship in balance of interaction among objects. As an ultimate law hiding objects, harmonious relation is the goal of management [21].

Oriental idea of harmony comprises harmony of people and harmony of objects [22]. The harmony of people describes interpersonal relationship, individual-group nexus and individual oneself as interaction attempting to achieve dynamic balance between internal harmony and external endeavor. Far and wide, harmony of objects, which is not only an objective manifestation but also subjective feelings, illustrates coopetition, multivariate coordination, and eventually win-win situation. Obviously, harmony of objects covers a broader range allowing more conflict.

\subsection{Harmony of People and Business Niche}

Personal harmony of employees is the fundament of harmonious business ecology reflecting in personal demands consistent with business vision. In case of contradiction between individual interest and organizational goal, all disagreement should be dealt by moderate means in order to minimizing the damage to the business. Hence, it is necessary that expanding human resource niche to help staffs adjust to the changing circumstance.

The harmonious interpersonal relation is one of features of balanced internal ecology. Staffs that are organized to achieve specific goal, are considered as subjects of equal footing, by oriental ideas on management, regardless of managers or those that are managed. A company's human resource niche can exert influence on the business niche by its entirety, openness, dynamics and correlation [23]. It is unconstrained and plenary human development that management is designed to but not traditional means aiming to domination.

Thanks to harmony of people within businesses, enterprises are able to achieve harmony of internal ecology integrating resources to compete by regulating their business niches. Transition of business niche is also affected by relationship among "people" that refers to relative enterprises. Besides, unhealthy competition should be avoided. Sustainable development of a company is based on its internal harmony, represented by its external harmony. In this view of management, handling the extent plays a pivotal role in replying with the objective law of management.

\subsection{Harmony of Objects}

Harmony of objects indicates the balanceable relation among various objects and factors and the mutual fusion. Ecological management of enterprises contains links, in which coopetition relationship exists, such as competitors, upstream and downstream. Existence of an enterprise relies on its economic and social network in which it collaborates and competes with others. Therefore, reducing the overlap of business niche density and expanding the width of business niche will result in abatement of resources restrict and malignant competition.

Oriental ideas confirm that diversity which may produce variant conflicts is universal and contradiction 
should be settled by some consistent principles. The thought of harmony from oriental ideas directs adjustment of relation among rivals and alliance. Enterprises tend to a narrow niche in stable conditions and probably adopt a wide niche in multidimensional environment. Survivals in the same environment rarely take similar niches because the width of business niche determines the competitive degree.

Known as "Ren Wei Wei Ren", the essence of oriental idea of harmony directs coopetition relationship. "Ren Wei" that refers to active behaviors should be applied to illustrate a positive figure being helpful to establish partnership. "Wei Ren" exhibits a description of all involved parties' benefit and punishment. Game behaviors of ecological factors in business ecology system conform to "Ren Wei Wei Ren" theory which results in viewing business ecology in multiple coexistences. Enterprises need "Ren Wei" activity to obtain and adjust their initial business niches. Coexistence and separation of business niche is a symptom of "Wei Ren".

Oriental thought claims that harmony, which is both objective and subjective, originates in common distinction and connection among things. The Golden Mean, the classic ancient literature in China, indicates the criterion of harmony is coexistence of various objects. Enterprises and all the other ecological components are subject to the common law in order to achieve sustainability in the grand cycle consisting of economy, nature and society.

Due to anthropocentrism in occidental culture, it is easy to understand conflicts between companies and external surroundings. Anthropocentrism accompanied with the inverse of supervising and being managed, enhances control and obedience in occidental management thought. Besides, control and obedience in economy or society also express as the duty of impelling individual to play a role of controller. The business niche adaption to ecological environment is passive under the view.

Oriental idea of harmony professes that harmonious status spontaneously shapes from within to outside. Enterprises initially achieve internal harmony before dealing with supply chains, communities, customers, competitors and natural environment. Dao, a Chinese word presenting the basic law in the universe, treats all elements in an ecological system as subjects of equal footing. Sweeping before one's floor, enterprises develop the harmony of business ecology.

\section{Application of Business Niche in Strategic Management: Based on Oriental Idea of Harmony}

\subsection{Self-Harmony of Enterprises}

Any enterprise will never obtain harmonious niche without optimized human resource niche. Human resource, which is the core of an enterprise's internal ecology, adapts a company for the vision-nature-niche circle [24]. Enterprises should inspire employees, stimulate innovation, develop values consistent with the vision and construct learning organizations. These measures make up the foundation of self-harmony of employees, accommodating business ecology, reform and development.

An employee's niche is significantly affected by the institutional design. A human resource niche with low overlap and wide breadth leads to more initiative, being harmonious internally and competitive externally. Locating individual niche of employees and focusing personal objects towards the organizational object are helpful in both individual achievement and organizational performance. As a result, the Gold Mean of Confucianism that is one of core ideologies of oriental ideas should be applied in strategic management. Initially the conception of proper limits should be erected. Then managers select the optimal measures and master them [22].

Owe to stable niches of subsystems, the whole business niche maintains dynamically stable status by combination of various departments. Enterprises ought to develop excellent institution and positive culture to preserve the steady state, in other words, the balance between hardness and flexibility is the fundament, in accordance with the Book of Changes which is one of the classics of Chinese culture. The business ecology system with both pliability and hardness has better environmental shock resistance, which is helpful to adjust its business niche.

Self-harmony of a business also relies on fair and appropriate measures, in which result the capacity of business ecology system. Separation and migration of business niche are subject to the doctrine of Golden Mean, which declines blindly asymmetric innovation and requires rational expansion. McDonald's, Enron, Tyco International Ltd., Start Group and Warren E. Buffett's investment principles are typical cases in this view. The concept of measure is the vital element that tends to obey moderate principle. The adjustment of business ecology has to adhere to "Dao". 


\subsection{Control of Business Niche}

The oriental idea of harmony inspires contemporary business niche by coopetition for win-win situation. In accordance with "Not Following the Same" originating from ancient Chinese culture, a group of companies will confront competition directly unless they are able to survive at a business niche with low overlap. The colony effect, which leads to disorderly competition resulting in saturated market and even losses in the entire industry, will appear in choosing niches. By upgrading value for customers, intelligence and knowledge are helpful to the expansion of business niche. It is occupying uncaptured niches that avoid excessive competition.

"Harmony but Not Sameness" illuminates interdependent relationship between enterprises, even if there is also competitive relation. In the short term, a narrow niche has low overlap which achieves high growth and self-harmony. However, dramatic changes of environment enhances the difficulty of survival in the long term because of resource scarcity along with narrow niches, besides, severe competition usually impels firms to spread their niches in order to gain more resource. Enterprises have to keep balance between both unsustainable situations aforementioned. Consequently reducing overlap of business niches and seeking for differentiation are necessary to weaken direct competition or involve them into a symbiosis relation. In one word, it is harmony or all-win.

\subsection{Harmony of Corporate Citizens}

A company is individually affected by elements such as government, customers, community and natural ecology, which consist of multidimensional factors to business niche. The oriental idea of harmony applied in politics develops the Harmonious Society which derives the Dream of China. Aiming at keeping business ecology wellbeing, enterprises also consider factors like demands from society and natural environment.

An enterprise is equal to other parts of business ecology under oriental view. Since Renaissance, the humanistic trends in occident have been dissimilated to anthropocentricism. In spite of great promotion of green technology, the fundamental opposition between human beings and nature remains. Oriental idea of harmony committing to "syncretism of the universe and human" characterizes by people oriented, morality preferential and "Ren Wei Wei Ren" behaviors. An enterprise with appreciate business niche will perform its role of a corporate citizen.

\section{Conclusion}

The main application of business niche in strategic management is primarily in competition strategy, piloting cooperation and surviving by differentiation. According to oriental idea of harmony, the theory of business niche unites friendly competition, sustainable development, intra-industrial collaboration and corporate social responsibility. Enterprises are able to live long in business ecology system based on the consolidation of the economic and social attribute.

\section{References}

[1] Grinnell, J. (1917) Field Test of Theories Concerning Distributional Control. The American Naturalist, 51, $115-128$. http://dx.doi.org/10.1086/279591

[2] Elton, C.S. (1927) Animal Ecology. University of Chicago Press, Chicago.

[3] Hutchinson, G.E. (1957) Concluding Remarks. Cold Spring Harbor Symposia on Quantitative Biology, 22, $415-427$. http://dx.doi.org/10.1101/SQB.1957.022.01.039

[4] Odum, E.P. (1983) Basic Ecology. CBS College Publishing, New York.

[5] Colinvaux, P. (1986) Ecology. John Wiley \& Sons Inc., New York.

[6] Liu, X. and Tan, L. (2003) Enterprises Have to Implement Management of Golden Mean. Economic Management, 5, 28-30.

[7] Baum, J.A.C. and Singh, J.V. (1994) Organizational Niche and the Dynamics of Organizational Mortality. American Journal of Sociology, 100, 346-380. http://dx.doi.org/10.1086/230540

[8] Liang, J., Ge, Z. and Fan, J. (2002) Enterprise Ecology and Enterprise Development. Journal of Management Sciences in China, 2, 34-40.

[9] Hannan, M.T. and Freeman, J. (1984) Structural Inertia and Organizational Change. American Sociological Review, 49, 149-164. http://dx.doi.org/10.2307/2095567 
[10] Stuart, T.E. and Podolny, J.M. (1996) Local Search and the Evolution of Technological Capabilities. Strategic Management Journal, 17, S21-S38. http://dx.doi.org/10.1002/smj.4250171004

[11] Kimura, Y. (1989) Firm-Specific Strategic Advantages and Foreign Direct Investment Behavior of Firms: The Case of Japanese Semiconductor Firms. Journal of International Business Study, 20, 296-314. http://dx.doi.org/10.1057/palgrave.jibs.8490360

[12] Eisenhardt, K.M. and Galunic, D.C. (2000) Coevolving: At Last, a Way to Make Synergies Work. Harvard Business Review, 1, 91-101.

[13] Puranam, P., Alexy, O. and Reitzig, M. (2014) What's “New” about New Forms of Organizing? Academy of Management Review, 39, 162-180. http://dx.doi.org/10.5465/amr.2011.0436

[14] Dobrev, S.D., Kim, T.-Y. and Carroll, G.R. (2002) The Evolution of Organizational Niches: U.S. Automobile Manufactures 1885-1981. Administrative Science Quarterly, 47, 233-264. http://dx.doi.org/10.2307/3094805

[15] Yang, H. and Lu, W.S. (2013) Niche Comparisons: Toward a New Approach for Analyzing Competition and Organizational Performance in the International Construction Market. Construction Management and Economics, 31, 307-321. http://dx.doi.org/10.1080/01446193.2013.777753

[16] Hannan, M.T. (1997) Inertia, Density, and the Structure of Organizational Populations: Entries in European Automobile Industries, 1886-1991. Organization Studies, 18, 193-228. http://dx.doi.org/10.1177/017084069701800202

[17] Doz, Y.L. (1996) The Evolution of Cooperation in Strategic Alliances: Initial Conditions or Learning Processes. Strategic Management Journal, 17, 55-83. http://dx.doi.org/10.1002/smj.4250171006

[18] Hodgson, G.M. (2013) Understanding Organizational Evolution: Toward a Research Agenda Using Generalized Darwinism. Organization Studies, 34, 973-992. http://dx.doi.org/10.1177/0170840613485855

[19] Bruggeman, J., Grunow, D., Leenders, M.A.A.M., Vermeulen, I. and Kuilman, J.G. (2012) Market Positioning: The Shifting Effects of Niche Overlap. Industrial and Corporate Change, 21, 1452-1477. http://dx.doi.org/10.1093/icc/dts009

[20] Liu, X., Jin, P. and Yu, D. (2008) A New Exploration on Management Function and Competitive Strategy Based on Niche. Ecological Economy, 1, 52-55.

[21] Su, D. (2005) Oriental Management. Fudan University Press, Shanghai, 226 p.

[22] Su, Z. (2009) Tutorial of Oriental Management. Shanghai University of Finance and Economics Press, Shanghai, 335337.

[23] James, H.S., Klein, P.G. and Sykuta, M.E. (2011) The Adoption, Diffusion and Evolution of Organizational Form: Insights from the Agrifood Sector. Managerial and Decision Economics, 32, 243-259. http://dx.doi.org/10.1002/mde.1531

[24] Yu, H.H. and Shih, W.C. (2014) Taiwan’s PC Industry, 1976-2010: The Evolution of Organization Capability. Business History Review, 88, 329-357. 
Scientific Research Publishing (SCIRP) is one of the largest Open Access journal publishers. It is currently publishing more than 200 open access, online, peer-reviewed journals covering a wide range of academic disciplines. SCIRP serves the worldwide academic communities and contributes to the progress and application of science with its publication.

Other selected journals from SCIRP are listed as below. Submit your manuscript to us via either submit@scirp.org or Online Submission Portal.
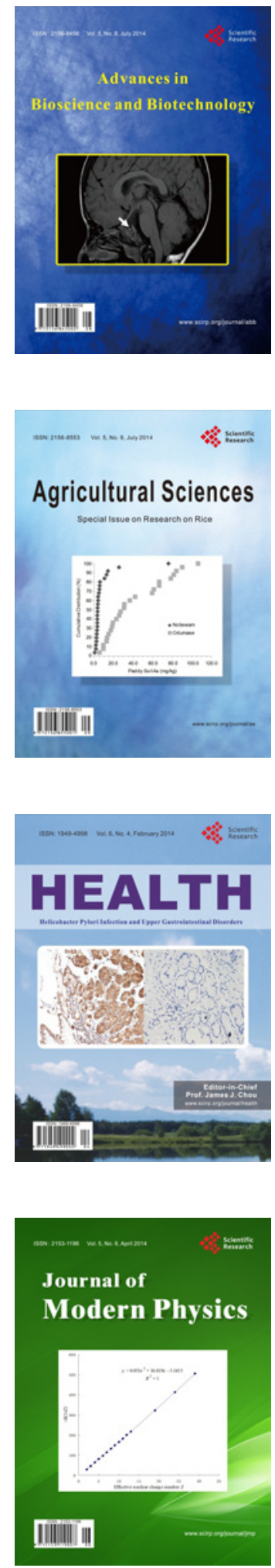
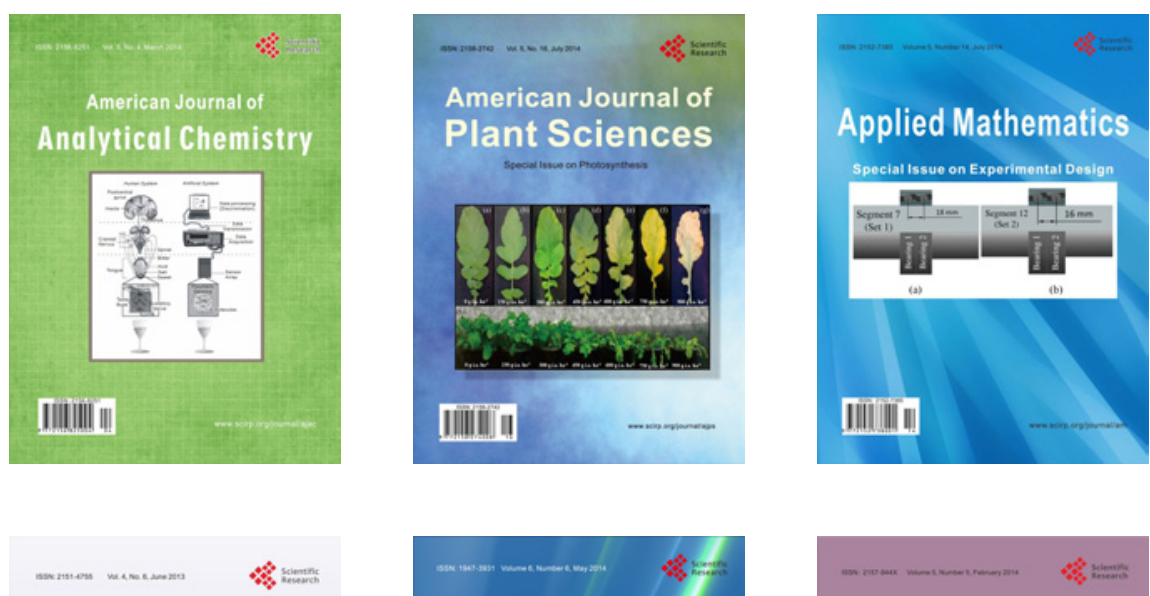

Creative Education
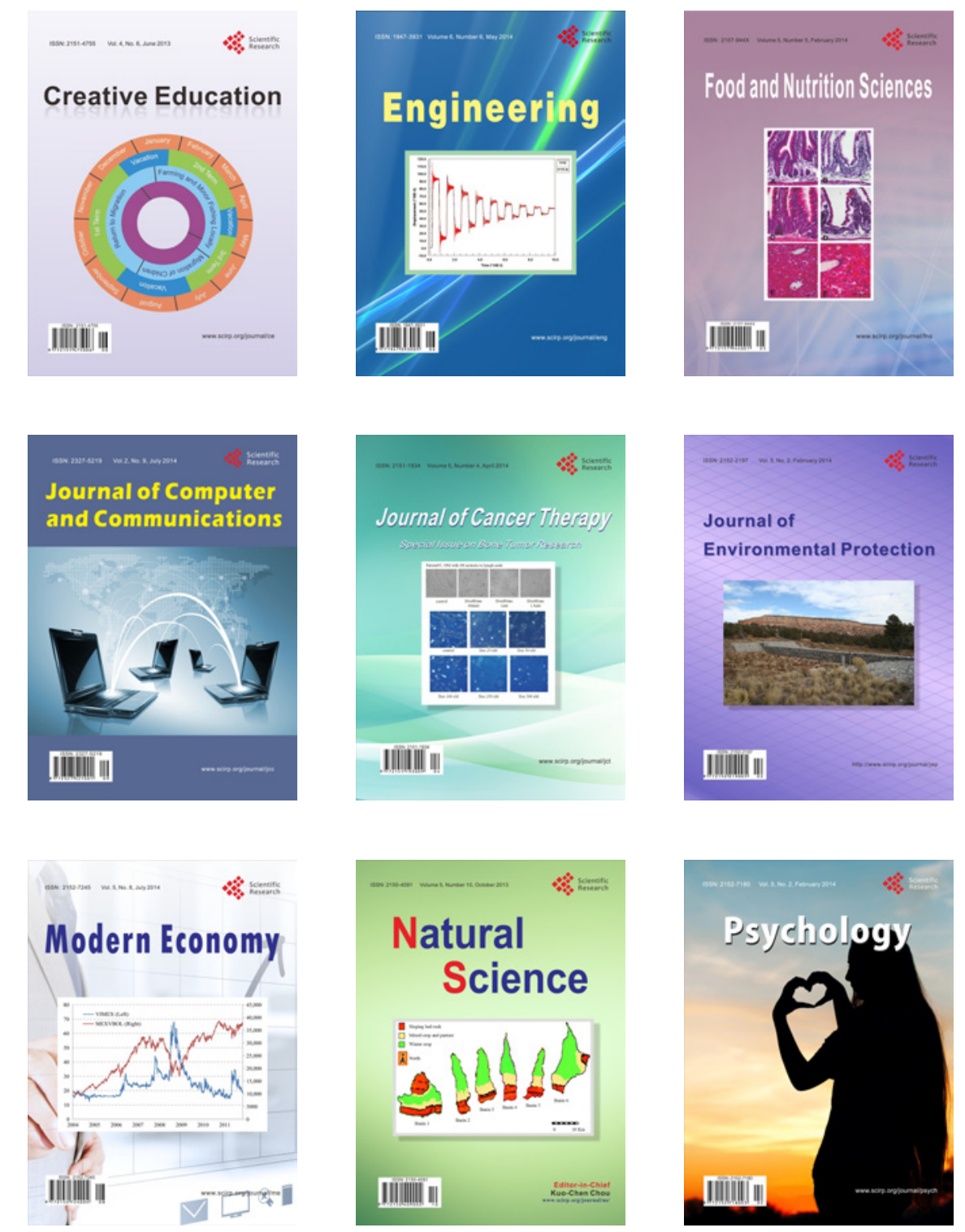